ORIGINAL ARTICLE

\title{
Relation between epistaxis, external nasal deformity, and septal deviation following nasal trauma
}

\author{
M Daniel, U Raghavan
}

Emerg Med J 2005;22:778-779. doi: 10.1136/emj.2004.018994

See end of article for authors' affiliations .....................

Correspondence to: Mat Daniel, Department of Otorhinolaryngology/ Head \& Neck Surgery, Leicester Royal Infirmary, Infirmary Square, Leicester, LE1 5WW, UK. mdaniel@doctors.org.uk

Accepted for publication 14 November 2004

\begin{abstract}
Objectives: To find if the presence of epistaxis after nasal trauma can be used to predict post-traumatic external nasal deformity or a symptomatic deviated nasal septum.

Methods: Retrospective analysis of all patients seen in the fractured nose clinic by the first author between 17 October 2003 and 27 February 2004. Presence of epistaxis, newly developed external nasal deformity, and the presence of a deviated nasal septum with new symptoms of nasal obstruction were noted.

Results: A total of 139 patients were included in the study. Epistaxis following injury was noted in 106 (76\%). Newly developed external nasal deformity was noted in 71 (51\%), and 33 (24\%) had a deviated nasal septum with new symptoms of nasal obstruction. Of the 106 patients with post-trauma epistaxis, 50 (67\%) had newly developed external nasal deformity and of the 33 patients without post-traumatic epistaxis, $11(33 \%)$ had nasal deformity $(p<0.05)$. Post-trauma epistaxis was not associated with the presence of a newly symptomatic deviated septum (25\% in patients with epistaxis after injury versus $18 \%$ if there was no epistaxis).

Conclusions: Presence of epistaxis after nasal trauma is associated with a statistically significant increase in external nasal deformity. However, one third of patients without epistaxis following nasal trauma also had external nasal deformity and hence all patients with a swollen nose after injury, irrespective of posttrauma epistaxis, still need to be referred to the fractured nose clinic.
\end{abstract}

$\mathrm{N}$ asal injuries are a common complaint seen in the Accident and Emergency department; indeed, nasal fractures are the most common type of facial fractures. ${ }^{12}$ Because of initial post-traumatic swelling, it is often difficult to decide whether there will be an external nasal deformity and/or a deviated nasal septum once the initial swelling settles down. Hence, all patients with a suspected nasal fracture are referred to the ear, nose, and throat department (ENT) where they are seen one to two weeks after injury and reassessed. If there is nasal deformity then manipulation can be undertaken ${ }^{3-6}$ to restore the appearance of the nose and function. ${ }^{7}$ The nose is the central and most dominant feature of the face, and even millimetres of nasal deviation are easily evident even to the most casual of observers. ${ }^{3}$

Fractures can be classified as open or closed, depending on the integrity of the skin or mucosa. ${ }^{48}$ Epistaxis commonly accompanies nasal injuries. Presence of epistaxis usually indicates a disruption of mucosa and possible nasal bone or septal fracture, ${ }^{7}$ but bleeding may be concealed as well as revealed. However, the relation between the epistaxis and nasal bone and/or septal fracture has not been reported and a search of world literature failed to find one. This study was done to find out if the presence of post-trauma epistaxis is associated with external nasal deformity or a symptomatic deviated nasal septum. We hypothesised that the presence of epistaxis following nasal trauma would be related to a possible fracture of nasal bone or septum. Such a relationship may be of clinical relevance for the Accident and Emergency department or the general practitioner when deciding who to refer to fractured nose clinic.

\section{METHODS}

All patients seen in the Leicester Royal Infirmary fractured nose clinic by the first author (MD) between 17 October 2003 and 27 February 2004 were included in this retrospective study. This is a special clinic designed for the early assessment and management of fractured nasal bones. The patients were referred to the clinic, either by Accident and Emergency or by the general practitioner, because of nasal trauma that resulted in a suspected nasal fracture; all patients had nasal swelling and/or deformity in the first few days after the injury. When patients were seen in the fractured nose clinic, one to two weeks later, sufficient time had usually elapsed for external and internal swelling to subside (if there was still a lot of soft tissue swelling, patients were seen again in a week). Information was collected on the patients' age and sex, presence and duration of epistaxis, external nasal deformity that occurred after the recent trauma, new nasal obstruction, deviated nasal septum, and need for manipulation. Because of the high incidence of asymptomatic deviated nasal septum in the general population, we classified people that had both a deviated septum and new nasal obstruction since the injury as "newly symptomatic deviated nasal septum", and used this for purposes of analysis. In children too young to comment themselves on nasal obstruction, parent's opinion was sought and nasal patency tested by means of a cold mirror placed under the nares. Statistical analysis (Pearson $\chi^{2}$ test) was performed using SPSS.

\section{RESULTS}

A total of 139 patients were included in the study: 91 (65\%) men and $48(35 \%)$ women. The ages ranged from 1-90 years, with a mean of 29 years. Of 139 patients, 106 (76\%) had epistaxis following the injury and 33 (24\%) did not; none of the patients with post-trauma epistaxis required admission.

At the ENT clinic visit, 71 (51\%) had external nasal deformity whereas 68 (49\%) did not. Table 1 illustrates the relation between post-trauma epistaxis and final external

Abbreviations: ENT, ear, nose, and throat 


\begin{tabular}{llll}
$\begin{array}{l}\text { Table } 1 \\
\text { deformity }\end{array}$ & Post-trauma epistaxis and final external nasal \\
\hline & Deformity & No deformity & Total \\
\hline Epistaxis & $60(57 \%)$ & $46(43 \%)$ & $106(100 \%)$ \\
No epistaxis & $11(33 \%)$ & $22(67 \%)$ & $33(100 \%)$ \\
Total & $71(51 \%)$ & $68(49 \%)$ & $139(100 \%)$ \\
\hline
\end{tabular}

nasal deformity. Patients that reported a history of posttrauma epistaxis were significantly more likely to have external nasal deformity when seen in the fracture nose clinic (Pearson $\chi^{2} \mathrm{p}<0.05$ ). The sensitivity of epistaxis as an indicator for external nasal deformity is $85 \%$ and the specificity is $32 \%$. Manipulation was carried out in 47 patients: $38(81 \%)$ under local anaesthetic and $9(19 \%)$ under general anaesthetic.

Of 139 patients, 33 (24\%) had a newly symptomatic deviated nasal septum, whereas 106 (76\%) did not. It is of interest that of the 56 patients with a deviated nasal septum, only 33 complained of nasal obstruction. Table 2 shows the relation between post-trauma epistaxis and the presence of a newly symptomatic deviated nasal septum. Post-trauma epistaxis was not related to the incidence of newly symptomatic deviated septum, or to the incidence of any deviated septum seen in the fracture nose clinic (as tested by Pearson $\left.\chi^{2}\right)$.

\section{DISCUSSION}

We investigated whether epistaxis in cases of suspected nasal fracture is associated with final external nasal deformity or a symptomatic deviated nasal septum. We postulated that the presence of epistaxis may be an indicator of a fractured nasal bone or nasal septum. Conversely, if the data showed that none of the patients with nasal deformity or a newly symptomatic deviated nasal septum suffered epistaxis after their injury, then patients seen in Accidents and Emergency with a swollen nose after trauma but no epistaxis could be reassured that they have probably not sustained a serious injury.

Certainly, this study shows a statistically significant relation between the presence of post-traumatic epistaxis and an eventual external nasal deformity $(p<0.05)$. However, this association does not have a clinical significance as there are a significant number of patients that have no epistaxis yet suffer external deformity (33\%). Further, there may be many people with post-trauma epistaxis that have no external nose changes, and would therefore not be referred to the fractured nose clinic at all; with this, the relevance of epistaxis as a marker of severity of injury would be even smaller.
Table 2 Post-trauma epistaxis and a newly symptomatic deviated nasal septum

\begin{tabular}{llll}
\hline & Symptomatic DNS & $\begin{array}{l}\text { No symptomatic } \\
\text { DNS }\end{array}$ & Total \\
\hline Epistaxis & $27(25 \%)$ & $79(75 \%)$ & $106(100 \%)$ \\
No epistaxis & $6(18 \%)$ & $27(82 \%)$ & $33(100 \%)$ \\
Total & $33(24 \%)$ & $106(76 \%)$ & $139(100 \%)$ \\
\hline
\end{tabular}

The no symptomatic deviated septum group includes patients with a straight nasal septum as well as those with a deviated septum but no new symptoms of nasal obstruction. DNS, deviated nasal septum.

In conclusion, epistaxis after injury that results in a swollen nose cannot be used to predict which patients will end up with external nasal deformity or a deviated septum with new symptoms of nasal obstruction. All patients with a swollen/deformed nose after injury, or symptoms/signs of nasal obstruction, should be referred to the fractured nose clinic irrespective of the presence of epistaxis.

\section{Authors' affiliations}

M Daniel, U Raghavan, Department of Otorhinolaryngology/Head \& Neck Surgery, Leicester Royal Infirmary

\section{Competing interests: none declared}

"The Corresponding Author has the right to grant on behalf of all authors and does grant on behalf of all authors, an exclusive licence (or non exclusive for government employees) on a worldwide basis to the BMJ Publishing Group Ltd to permit this article (if accepted) to be published in Emergency Medicine Journal and any other BMJPGL products and sublicences such use and exploit all subsidiary rights, as set out in our licence (http://EMJ.bmijournals.com/misc/ifora/licenceform.shtml)."

\section{REFERENCES}

1 Muraoka M, Nakai Y. Twenty years of statistics and observation of facial bone fracture. Acta Otolaryngol Suppl 1998;538:261-5.

2 O'Donoghue GM, Vaughan EDV, Condon KC. An analysis of the pattern of facial injuries in a general accident department. Injury $1979 ; 11: 52-61$.

3 Fernandes SV. Nasal fractures: the taming of the shrewd. Laryngoscope 2004;114:587-92.

4 Courtney MJ, Rajapakse Y, Duncan G, et al. Nasal fracture manipulation; a comparative study of general and local anaesthesia techniques. Clin Otolaryngol 2003;28:472-5.

5 Cook JA, Murrant NJ, Evans KL, et al. Manipulation of the fractured nose under local anaesthesia. Clin Otolaryngol 1992;17:337-40

6 Murray JAM, Maran AGD. The treatment of nasal injuries by manipulation. $J$ Laryngol Otol 1980;94:1405-10.

7 Reinbolt RL, Welch RD. Nasal fracture. emedicine, 2004. http:// www.emedicine.com/sports/topic84.htm (accessed 29 July 2005).

8 Ross AT, Becker DG. Fractures, nasal and septal. emedicine, 2004. http://www.emedicine.com/ent/topic159.htm (accessed 29 July 2005) 